Article

\title{
The Impact of Water Quality on the Use of Solar Water Heaters in Remote Islands of Taiwan
}

\author{
Kai-Chun Fan, Keh-Chin Chang * and Kung-Ming Chung \\ Energy Research Center, National Cheng Kung University, Tainan 701, Taiwan; kinu1216@gmail.com (K.-C.F.); \\ kmchung@mail.ncku.edu.tw (K.-M.C.) \\ * Correspondence: kcchang@mail.ncku.edu.tw; Tel.: +886-6-275-7575
}

Academic Editors: Ling Tim Wong and Kwok Wai Mui

Received: 12 October 2016; Accepted: 10 November 2016; Published: 15 November 2016

\begin{abstract}
The use of solar water heaters (SWHs) in Taiwan's remote islands has been subjected to scaling and, in particular, corrosion problems due to sources of water. In this study, four different water quality indices including the Langelier Saturation Index (LSI), the Ryznar Stability Index (RSI), the Puckorius Scaling Index (PSI), and the Larson-Skold Corrosive Index (LSCI) were employed to assess the scaling and corrosion tendencies in SWHs caused by tap water and ground water in the Penghu, Kinmen, and Lienchiang counties, each of which is constituted of several remote islands. In general, the LSI, the RSI, and the PSI results show a slight scaling tendency in Penghu, but a corrosion tendency in Kinmen and Lienchiang. Nevertheless, all LSCI results show a serious steel corrosion tendency in these three counties. In addition, the chloride ion $\left(\mathrm{Cl}^{-}\right)$concentrations are higher than $45 \mathrm{mg} / \mathrm{L}$ in either tap water (except for the Lieyu township in Kinmen) or ground water. This fact resulted in serious corrosion problems, as found in the currently installed SWHs, which were mainly made from 304 stainless steel. The metals with higher corrosion resistance to chloride ions are required in the manufacture of SWHs to be installed on these three remote-island counties.
\end{abstract}

Keywords: water quality index; Langelier Saturation Index (LSI); Larson-Skold Corrosive Index (LSCI); corrosion; solar water heater; remote island

\section{Introduction}

Solar thermal energy is widely used in many countries [1]. Solar water heaters (SWHs) are mainly composed of four parts: a solar collector, a water storage tank, piping, and a control system. The absorbing plate is generally made of copper, aluminum, stainless steel, or flexible polymer. Packing material between inside and outside barrels for a stainless-steel water storage tank is for thermal insulation. In Taiwan, the climatic conditions are predominantly sunny. The solar radiation ranges from 1200 to $1700 \mathrm{kWh} / \mathrm{m}^{2}$ /year. To disseminate SWHs, the Bureau of Energy, Ministry of Economic Affairs (BEMOEA, the first-stage national subsidy program: 1986-1991; the second-stage national subsidy program: 2000-present) and some regional governments have offered subsidy programs [2]. The Energy Research Center at National Cheng Kung University (ERC/NCKU) has been authorized by the BEMOEA to organize an operation unit for the second national subsidy program starting in 2000. The accumulated area of solar collectors installed between 2000 and 2015 reached 1.62 million $\mathrm{m}^{2}$. Taiwan, as a country (officially named Republic of China), is composed of a main island (named Taiwan island) and quite a few remote islands as shown in Figure 1. There are three counties, namely Penghu, Kinmen, and Lienchiang, which are located out of the main island and constituted by remote islands. Note that the Low Carbon Island Project, including the Penghu and Kinmen counties, was also launched in 2012 and aimed at reducing the production of carbon dioxide in the remote islands of Taiwan. Promotion of SWHs was an initiative of the Project [3]. 


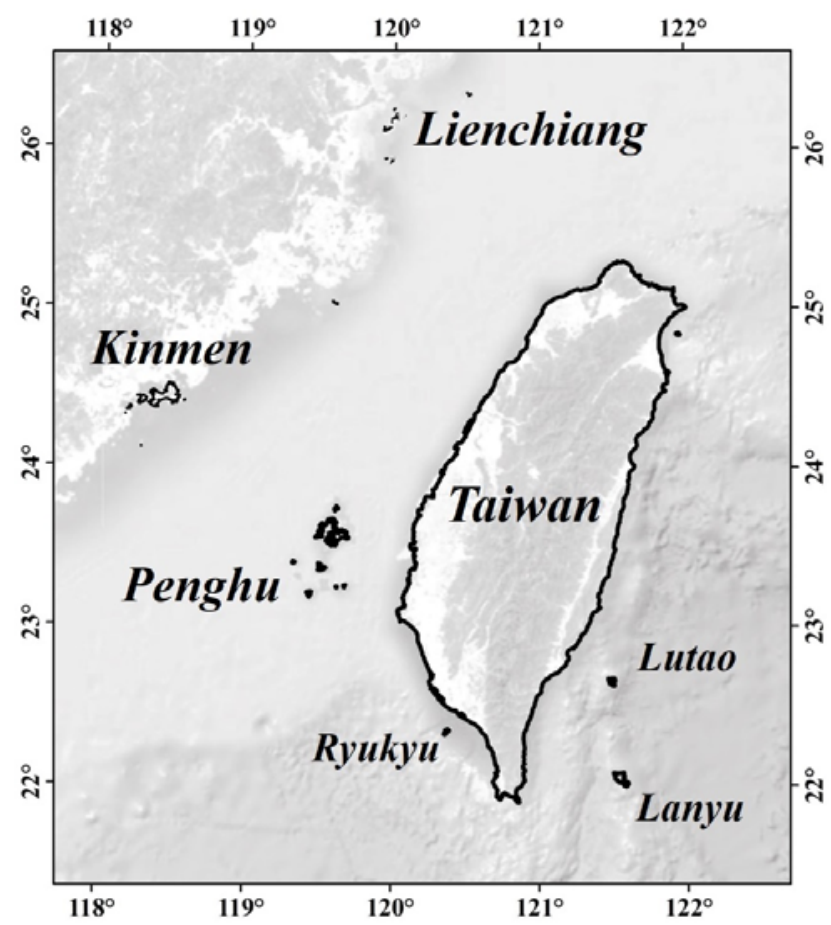

Figure 1. Map of Taiwan and its remote islands.

A survey of promotion outcome of SWHs is of great concern to end users. In 2013, telephone interviews were conducted by the ERC/NCKU for 6482 SWHs installed in 2000, in which 3379 end users $(52.1 \%)$ were reached. The survey showed that there were $95.3 \%$ systems in operation for 12 years at least. However, malfunctions of SWHs have been reported from time to time. In the period of 2000-2012, 942 cases were documented by the ERC/NCKU, in which 555 of them (58.9\%) were damaged with leakage (corrosion or pitting) in absorbing plates, gate valves, storage tanks, or pipe joints.

In the main island of Taiwan, water resources are rich. Tap water is the principal domestic water supply (the population percentage is $91.56 \%$ in 2013) [4], and its water quality is stable. In contrast, the principal domestic water sources in the remote islands are the tap water made mainly from desalination, ground water, or both [3]. To assess the water quality in SWHs in the remote islands, this study sampled tap water and ground water from households with SWHs in the three counties constituted of the remote islands, namely Penghu, Kinmen, and Lienchiang. Analyses of water quality were conducted, including the parameters of $\mathrm{pH}$, total alkalinity, total hardness, chloride, and sulfate. The water quality assessments by means of the methods of the Langelier Saturation Index (LSI), the Ryznar Stability Index (RSI), the Puckorius Scaling Index (PSI), and the Larson-Skold Corrosive Index (LSCI) were employed to estimate the tendency of scaling or corrosion [5-14]. The values of the LSI, the RSI, and the PSI are primarily used to estimate the scaling potential of calcium carbonate $\left(\mathrm{CaCO}_{3}\right)$ in water [14]. Among these three methods, LSI is a forerunner and the most commonly used one [11]. However, Seneviratne [11] argued that LSI does not take into account the corrosivity of water because corrosion may still occur due to dissolved oxygen and solids such as chlorides or sulfates that increase the conductivity of water and corrosion rates. In contrast, the LSCI method proposed by Larson and Skold [7] is suitable for assessing the corrosiveness of water on low-carbon steel. In this study, the water quality assessment is made with the LSI, RSI, PSI, and LSCI methods to estimate the levels of scaling and corrosion tendencies for either tap water or ground water sampled from SWHs in Penghu, Kinmen, and Lienchiang. 


\section{SWHs Installed in the Three Remote-Island Counties}

As shown in Figure 1, Penghu $\left(119^{\circ} 19^{\prime}-119^{\circ} 43^{\prime}\right.$ E, $\left.23^{\circ} 12^{\prime}-23^{\circ} 47^{\prime} \mathrm{N}\right)$, with 37,151 households, straddles the Tropic of Cancer (along $23^{\circ} 30^{\prime} \mathrm{N}$ ). There are five townships (Husi, Baisha, Siyu, Wang-An, and Chimei) and one city (Magong). Kinmen $\left(118^{\circ} 24^{\prime}-119^{\circ} 28^{\prime} \mathrm{E}, 24^{\circ} 27^{\prime}-24^{\circ} 59^{\prime} \mathrm{N}\right)$, with 36,558 households, is made up of 12 jurisdictional islands and is located in the subtropical oceanic climate zone. There are six townships (Jincheng, Jingsha, Jinhu, Jinning, Lieyu, and Wuqiu). Lienchiang $\left(119^{\circ} 54^{\prime}-120^{\circ} 30^{\prime} \mathrm{E}, 25^{\circ} 56^{\prime}-26^{\circ} 44^{\prime} \mathrm{N}\right)$, with 2423 households, which also lies within the subtropical oceanic climate zone, is the smallest county in Taiwan. There are four townships (Nangan, Beigan, Jyuguang, and Dongyin), of which Juguang is composed of two remote islands: Dongju Island and Xiju Island.

As previously mentioned, scaling and corrosion problems are of great concern for the promotion of SWHs in the remote islands of Taiwan. For instance, pipe blockage has stemmed from scaling (Figure 2a, calcium carbonate analyzed by $\mathrm{X}$-ray diffraction (XRD)). Figure $2 \mathrm{~b}$ shows pitting near the weld on a storage tank that is made from 304 stainless steel. The maximum diameter of pitting hole was larger than $1 \mathrm{~mm}$. It has recently been reported [15] that aragonite, which is a crystalline phase of the calcium carbonate scales, can be formed at a temperature in the range of $50-55^{\circ} \mathrm{C}$ and causes severe pitting corrosion. The XRD results indeed show the existence of aragonite in the scales, shown in Figure 2a. This may be one of the causes of the pitting corrosion problem. Figure 2c shows the leaks (due to corrosion) and its subsequent scaling on the absorption plate (made from 304 stainless steel). The pitting problem shown in Figure $2 b$ was attributed to poor welding in the manufacturing processes in addition to the water environments of high chloride concentration and high temperature (in summer), which aggravates the corrosion rate of the welding materials.
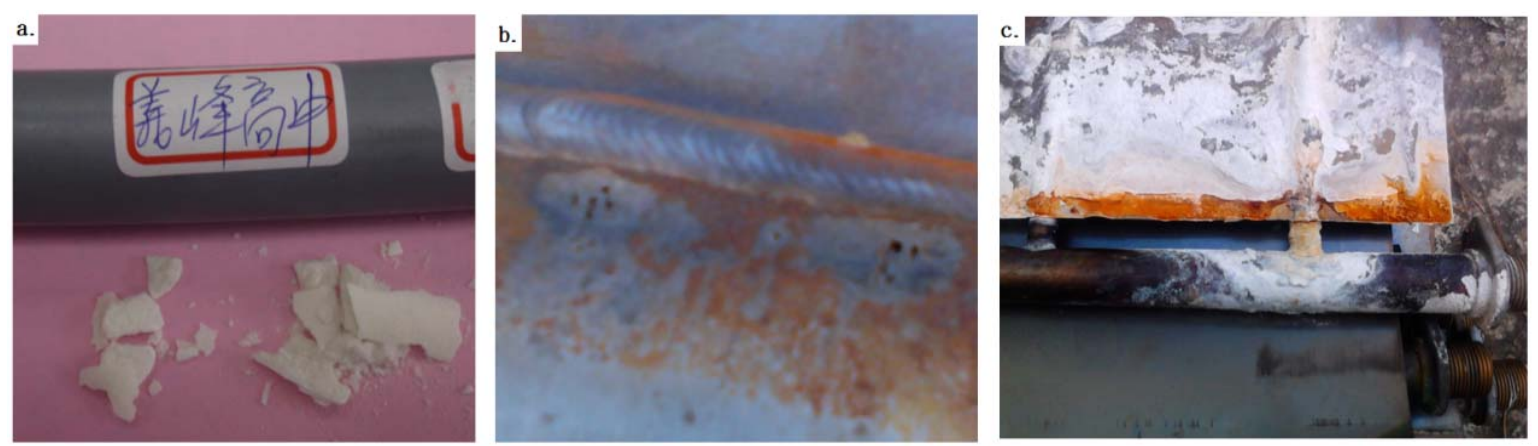

Figure 2. (a) Scaling in the connecting pipe; (b) pitting corrosion near the weld on storage tank; (c) corrosion and scaling on solar collector.

\section{Assessment Methods-Water Quality Index}

Data on the quality of tap water and ground water were obtained from the households with SWHs installed in 2013 and 2014. LSI, RSI, PSI, and LSCI were employed to assess the tendency of scaling or corrosion in SWHs. All chemical analyses required in the present study of water quality were made by the Sustainable Environment Research Center at NCKU, which is a certified unit by Environmental Analysis Laboratory, Environmental Protection Agency (EPA) of Taiwan.

\subsection{LSI Assessment Method}

Langelier [5] proposed a procedure for calculating the degree of saturation of water with respect to calcium carbonate, known as the Langelier Saturation Index (LSI). Prisyazhniuk [12] pointed out that the LSI makes it possible to estimate the ability of water to corrode steel, or the tendency of 
water to form scaling. Interpretation of the LSI given by the Carrier Air Conditioning Company [8] is compiled in Table 1. In the "Handbook of Drinking Water Quality" [16], the LSI is defined by

$$
\mathrm{LSI}=\mathrm{pH}-\mathrm{pH}_{\mathrm{S}}
$$

where $\mathrm{pH}$ is measured in a solution of hydrogen ion activity; $\mathrm{pH}_{\mathrm{S}}$ is a saturated hydrogen ion activity in either a calcite or a calcium carbonate solution and is determined by

$$
\mathrm{pH}_{\mathrm{S}}=(9.3+\mathrm{A}+\mathrm{B})-(\mathrm{C}+\mathrm{D})
$$

where

$\mathrm{A}=\left(\log _{10}(\mathrm{TDS})-1\right) / 10 ;$ TDS: total dissolved solids, $\mathrm{mg} / \mathrm{L}$;

$\mathrm{B}=-13.12 \log _{10}(\mathrm{~T}+273)+34.55 ; \mathrm{T}$ : temperature, ${ }^{\circ} \mathrm{C}$;

$\mathrm{C}=\log _{10}$ (Hardness) $-0.4 ;$ Hardness, $\mathrm{mg} / \mathrm{L}$;

$\mathrm{D}=\log _{10}$ (Alkalinity); Alkalinity concentration, $\mathrm{mg} / \mathrm{L}$.

Table 1. Interpretation of the Langelier Saturation Index (LSI) [8].

\begin{tabular}{cc}
\hline LSI Value & Indication \\
\hline 2.0 & Scale forming but non corrosive \\
0.5 & Slightly scale forming and corrosive \\
0.0 & Balanced but pitting corrosion possible \\
-0.5 & Slightly corrosive but non-scale forming \\
-2.0 & Serious corrosion \\
\hline
\end{tabular}

\subsection{RSI Assessment Method}

The Ryznar Stability Index (RSI) was proposed by Ryznar [6]. The RSI index, defined in Equation (3), is based on the calcium carbonate saturation index in water and can estimate the ability of scaling or corrosion. Interpretation of the RSI is summarized in Table 2 [8].

$$
\mathrm{RSI}=2 \mathrm{pH}_{\mathrm{S}}-\mathrm{pH} \text {. }
$$

Table 2. Interpretation of the Ryznar Stability Index (RSI) [8].

\begin{tabular}{cc}
\hline RSI Value & Indication \\
\hline $4.0-5.0$ & Heavy scale forming \\
$5.0-6.0$ & Light scale forming \\
$6.0-7.0$ & Little scale forming or corrosive \\
$7.0-7.5$ & Corrosion significant \\
$7.5-9.0$ & Heavy corrosion \\
$>9.0$ & Corrosion intolerable \\
\hline
\end{tabular}

\subsection{PSI Assessment Method}

The Puckorius Scaling Index (PSI) was proposed by Puckorius [9]. The PSI is a modification of the RSI but with a similar interpretation for the RSI, as indicated in Table 2. When estimating the scaling or corrosion tendency of the solution, the PSI addresses the buffering capacity in water and the maximum quantity of precipitates that is formed at equilibrium state. Therefore, the equilibrium $\mathrm{pH}\left(\mathrm{pH}_{\mathrm{eq}}\right)$ is adopted, instead of $\mathrm{pH}$, in the definition of the PSI as

$$
\mathrm{PSI}=2 \mathrm{pH}_{\mathrm{S}}-\mathrm{pH}_{\mathrm{eq}}
$$


where $\mathrm{pH}_{\mathrm{eq}}$ is calculated by

$$
\mathrm{pH}_{\mathrm{eq}}=1.465 \times \log _{10}(\text { Alkalinity })+4.54
$$

The scaling tendency becomes more significant in the range of small PSI values $(<6.0)$ than RSI, whereas only corrosion tendency is observed for PSI $>6.0$. Therefore, the PSI value is considered to be more accurate, as compared to both the LSI and RSI values, in the assessment of water quality.

\subsection{LSCI Assessment Method}

It was reported that stainless steel, copper, and aluminum are subject to pitting corrosion under the environment of water that contains chloride ions [17-21]. Nevertheless, the LSI, the RSI, and the PSI do not consider the effects of chloride ions in their assessment of water quality. The Larson-Skold Corrosive Index (LSCI) was originally proposed to assess the corrosivity of water on low-carbon steel [7]. This index is defined as the ratio of equivalent parts per million (ppm) of sulfate $\left(\mathrm{SO}_{4}{ }^{2-}\right)$ and chloride $\left(\mathrm{Cl}^{-}\right)$to the ppm of alkalinity in the form of bicarbonate plus carbonate $\left(\mathrm{HCO}_{3}{ }^{-}+\mathrm{CO}_{3}{ }^{2-}\right)$ :

$$
\mathrm{LSCI}=\frac{\mathrm{C}_{\mathrm{Cl}^{-}}+\mathrm{C}_{\mathrm{SO}_{4}^{2-}}}{\mathrm{C}_{\mathrm{HCO}_{3}^{-}}+\mathrm{C}_{\mathrm{CO}_{3}^{2-}}}
$$

where $\mathrm{C}$ is the concentration in $\mathrm{mg} / \mathrm{L}$ (ppm).

Note that the LSCI does not consider temperature and $\mathrm{pH}$ buffering capacity as the factors affecting corrosion behavior. Interpretation of the LSCI on corrosion tendency of steel is summarized as follows [12]:

LSCI $<0.8$-chlorides and sulfates do not influence the natural formation of the protective film on steel surface;

$0.8<\mathrm{LSCI}<1.2$ - slight tendency of steel corrosion can be observed;

LSCI > 1.2—significant localized (pitting) corrosion of steel can be observed.

\section{Results and Discussion}

The water resources analyzed in the study were sampled from the SWH user sites in the three investigated counties constituted of remote islands in Taiwan. It was well agreed [10] that scale formation/corrosion becomes more significant as the water temperature is elevated. In the case of a $\mathrm{SWH}$, the temperature of $80^{\circ} \mathrm{C}$, which can be frequently reached in the summer of Taiwan, was used in the estimation of the B term in Equation (2).

As a contrast, the assessment of scaling/corrosion tendency of the tap water in the main (Taiwan) island (see Figure 1) was firstly performed using the available data of water quality reported in between November 2013 and October 2014 [22]. The calculated values of the LSI, the RSI, and the PSI are $0.72 \pm 0.58,6.15 \pm 0.88$, and $6.31 \pm 0.93$, respectively. Based on the judgments listed in Tables 1 and 2, the tap water quality on the main island of Taiwan is subject to slight scaling or corrosive tendency. Since the penetration of tap water on the main island is as high as $91.6 \%$ [4], the scaling and corrosion issues in the SWHs installed on the main island are not serious problems. The chloride ion concentrations of tap water on the main island fall within $8.25 \pm 0.64 \mathrm{mg} / \mathrm{L}$, which are far smaller than those measured in either tap water or ground water of the three investigated remote-island counties (cf. Tables 3-8). The corresponding LSCI values are $0.58 \pm 0.25$. Following the interpretation of the LSCI on steel corrosion tendency, the steel corrosion issue due to the chloride ions in tap water can be overlooked in the SWHs installed on the main island of Taiwan. 
Table 3. Summary of chemical analysis and the water quality index for tap water in Penghu.

\begin{tabular}{|c|c|c|c|c|c|c|}
\hline Township/City & Magong & Husi & Baisha & Siyu & Wang-an & Chimei \\
\hline Alkalinity, mg/L & $87.9 \pm 49.3$ & $69.6 \pm 40.0$ & $257.2 \pm 71.5$ & $81.0 \pm 5.3$ & $110.0 \pm 53.7$ & $116.0 \pm 5.7$ \\
\hline $\mathrm{pH}$ & $7.8 \pm 0.5$ & $7.7 \pm 0.3$ & $8.0 \pm 0.3$ & $7.2 \pm 0.1$ & $7.7 \pm 0.1$ & $7.8 \pm 0.3$ \\
\hline $\mathrm{Cl}^{-}, \mathrm{mg} / \mathrm{L}$ & $177.3 \pm 38.5$ & $176.1 \pm 24.3$ & $223.4 \pm 62.4$ & $127.3 \pm 7.5$ & $253.5 \pm 79.9$ & $281.5 \pm 13.4$ \\
\hline $\mathrm{SO}_{4}^{2-}, \mathrm{mg} / \mathrm{L}$ & $48.9 \pm 23.5$ & $49.5 \pm .9$ & $41.9 \pm 15.9$ & $11.7 \pm 4.7$ & $70.5 \pm 15.1$ & $38.5 \pm 3.0$ \\
\hline TDS, mg/L & $494.3 \pm 99.7$ & $473.6 \pm 112.6$ & $774.8 \pm 62.7$ & $338.0 \pm 3.5$ & $672.0 \pm 524.6$ & $788.5 \pm 31.8$ \\
\hline Hardness, mg/L & $111.0 \pm 61.0$ & $91.1 \pm 55.7$ & $126.5 \pm 34.2$ & $55.6 \pm 63.6$ & $172.5 \pm 79.9$ & $255.0 \pm 0.0$ \\
\hline $\mathrm{HCO}_{3}^{-}, \mathrm{mg} / \mathrm{L}$ & $86.9 \pm 48.7$ & $69.1 \pm 39.6$ & $254.8 \pm 71.4$ & $80.9 \pm 5.3$ & $109.4 \pm 53.3$ & $115.2 \pm 6.1$ \\
\hline $\mathrm{CO}_{3}^{2-}, \mathrm{mg} / \mathrm{L}$ & $0.9 \pm 1.0$ & $0.4 \pm 0.5$ & $2.4 \pm 1.7$ & $0.1 \pm 0.0$ & $0.6 \pm 0.4$ & $0.8 \pm 0.4$ \\
\hline LSI & $0.7 \pm 0.8$ & $0.3 \pm 0$ & $1.4 \pm$ & $-0.3 \pm 0.5$ & $1.0 \pm 0.5$ & $1.3 \pm 0.3$ \\
\hline RSI & $6.5 \pm 1.2$ & $7.0 \pm 0.9$ & $5.1 \pm 0.4$ & $7.8 \pm 0.9$ & $5.8 \pm 0.9$ & $5.3 \pm 0.3$ \\
\hline PSI & $7.0 \pm 1.5$ & $7.5 \pm 1.3$ & $5.0 \pm 0.7$ & $7.7 \pm 0.9$ & $6.1 \pm 1.2$ & $5.5 \pm 0.1$ \\
\hline LSCI & $3.7 \pm 2.6$ & $4.1 \pm 2.0$ & $1.2 \pm 0.8$ & $1.7 \pm 0.1$ & $3.2 \pm 1.0$ & $2.8 \pm 0.0$ \\
\hline
\end{tabular}

Table 4. Summary of chemical analysis and the water quality index for ground water in Penghu.

\begin{tabular}{|c|c|c|c|c|c|c|}
\hline Township/City & Magong & Husi & Baisha & Siyu & Wang-an * & Chimei \\
\hline Alkalinity, mg/L & $153.0 \pm 40.0$ & $177.3 \pm 128.7$ & $286.0 \pm 107.0$ & $138.5 \pm 78.5$ & 144.0 & $287.5 \pm 13.4$ \\
\hline $\mathrm{pH}$ & $8.4 \pm 0.3$ & $7.5 \pm 0.4$ & $8.0 \pm 0.3$ & $7.7 \pm 0.3$ & 7.4 & $7.9 \pm 0.0$ \\
\hline $\mathrm{Cl}^{-}, \mathrm{mg} / \mathrm{L}$ & $306.8 \pm 151.8$ & $203.0 \pm 89.9$ & $254.7 \pm 67.0$ & $214.0 \pm 116.0$ & 893.0 & $236.5 \pm 46.0$ \\
\hline $\mathrm{SO}_{4}^{2-}, \mathrm{mg} / \mathrm{L}$ & $37.3 \pm 16.8$ & $35.1 \pm 7.6$ & $66.5 \pm 15.8$ & $114.9 \pm 138.7$ & 7.7 & $124.5 \pm 33.2$ \\
\hline TDS, mg/L & $764.8 \pm 309.4$ & $562.8 \pm 146.5$ & $842.7 \pm 206.5$ & $616.0 \pm 390.3$ & 2050.0 & $1018.0 \pm 53.7$ \\
\hline Hardness, mg/L & $127.6 \pm 77.7$ & $185.2 \pm 109.2$ & $224.0 \pm 109.3$ & $135.5 \pm 163.4$ & 332.0 & $242.5 \pm 99.7$ \\
\hline $\mathrm{HCO}_{3}^{-}, \mathrm{mg} / \mathrm{L}$ & $149.0 \pm 41.0$ & $176.5 \pm 128.2$ & $283.3 \pm 107.8$ & $137.5 \pm 77.5$ & 143.7 & $285.3 \pm 13.5$ \\
\hline $\mathrm{CO}_{3}^{2-}, \mathrm{mg} / \mathrm{L}$ & $3.8 \pm 1.9$ & $0.7 \pm 0.6$ & $2.7 \pm 0.7$ & $0.9 \pm 0.9$ & 0.3 & $2.2 \pm 0.0$ \\
\hline LSI & $1.6 \pm 0.2$ & $0.8 \pm 1.1$ & $1.7 \pm 0.1$ & $0.7 \pm 1.3$ & 1.0 & $1.7 \pm 0.2$ \\
\hline RSI & $5.2 \pm 0.5$ & $5.9 \pm 1.9$ & $4.5 \pm 0.6$ & $6.3 \pm 2.3$ & 5.4 & $4.5 \pm 0.4$ \\
\hline PSI & $5.9 \pm 0.9$ & $5.7 \pm 2.2$ & $4.5 \pm 1.2$ & $6.5 \pm 2.4$ & 5.0 & $4.3 \pm 0.4$ \\
\hline LSCI & $2.4 \pm 1.1$ & $2.4 \pm 2.7$ & $1.2 \pm 0.5$ & $2.2 \pm 0.6$ & 6.3 & $1.3 \pm 0.0$ \\
\hline
\end{tabular}

Note: * Single sample.

Table 5. Summary of chemical analysis and the water quality index for tap water in Kinmen.

\begin{tabular}{|c|c|c|c|c|c|}
\hline Township & Jincheng & Jinhu & Jinsha & Jinning & Lieyu * \\
\hline Alkalinity, mg/L & $35.0 \pm 10.4$ & $66.4 \pm 9.7$ & $61.5 \pm 26.7$ & $36.3 \pm 14.3$ & 56.0 \\
\hline $\mathrm{pH}$ & $6.3 \pm 0.5$ & $7.1 \pm 0.4$ & $7.5 \pm 0.4$ & $6.2 \pm 0.7$ & 6.9 \\
\hline $\mathrm{Cl}^{-}, \mathrm{mg} / \mathrm{L}$ & $54.3 \pm 15.5$ & $104.5 \pm 28.0$ & $1.2 \pm 54.1$ & $45.2 \pm 2.9$ & 5.5 \\
\hline $\mathrm{SO}_{4}^{2-}, \mathrm{mg} / \mathrm{L}$ & $15.7 \pm 15.6$ & $72.1 \pm 27.9$ & $68.4 \pm 32.9$ & $17.5 \pm 33.3$ & 5.1 \\
\hline TDS, mg/L & $204.2 \pm 58.6$ & $387.4 \pm 45.8$ & $355.2 \pm 143.8$ & $185.8 \pm 43.4$ & 203.0 \\
\hline Hardness, mg/L & $36.5 \pm 12.3$ & $122.8 \pm 20.3$ & $106.4 \pm 42.1$ & $28.0 \pm 6.1$ & 36.0 \\
\hline $\mathrm{HCO}_{3}^{-}, \mathrm{mg} / \mathrm{L}$ & $35.0 \pm 10.4$ & $66.3 \pm 9.7$ & $61.3 \pm 26.8$ & $36.3 \pm 14.3$ & 56.0 \\
\hline $\mathrm{CO}_{3}^{2-}, \mathrm{mg} / \mathrm{L}$ & $0.0 \pm 0.0$ & $0.1 \pm 0.1$ & $0.2 \pm 0.2$ & $0.0 \pm 0.0$ & 0.0 \\
\hline LSI & $-1.6 \pm 0.6$ & $0.0 \pm 0.3$ & $0.2 \pm 0.4$ & $-1.8 \pm 0.8$ & -0.8 \\
\hline RSI & $9.5 \pm 0.8$ & $7.1 \pm 0.4$ & $7.0 \pm 0.7$ & $9.8 \pm 1.0$ & 8.4 \\
\hline PSI & $9.0 \pm 0.7$ & $7.0 \pm 0.4$ & $7.4 \pm 1.0$ & $9.2 \pm 0.7$ & 8.2 \\
\hline LSCI & $2.0 \pm 0.4$ & $2.8 \pm 1.0$ & $2.7 \pm 0.8$ & $1.7 \pm 0.4$ & 0.2 \\
\hline
\end{tabular}

Note: * Single sample.

Due to the prevention of salt damage, which is a serious problem encountered in all the remote islands, almost all of the SWHs installed in the three investigated remote-island counties were made from 300-series stainless steels. Among them, most are made from 304 stainless steel, and few from 316 stainless steel. Thus, the following discussion will be focused on the corrosivity of these two 300 -series stainless steels that are due to the chloride ions in the water. 
Table 6. Summary of chemical analysis and the water quality index for ground water in Kinmen.

\begin{tabular}{|c|c|c|c|c|c|}
\hline Township & Jincheng & Jinhu & Jinsha & Jinning & Lieyu \\
\hline Alkalinity, mg/L & $84.7 \pm 103.7$ & $81.2 \pm 46.8$ & $109.5 \pm 68.8$ & $11.0 \pm 7.6$ & $136.7 \pm 35.5$ \\
\hline $\mathrm{pH}$ & $5.5 \pm 1.1$ & $6.3 \pm 0.9$ & $6.7 \pm 1.0$ & $4.8 \pm 0.6$ & $6.6 \pm 0.2$ \\
\hline $\mathrm{Cl}^{-}, \mathrm{mg} / \mathrm{L}$ & $69.0 \pm 39.8$ & $99.6 \pm 46.6$ & $167.0 \pm 20.2$ & $75.2 \pm 40.1$ & $106.1 \pm 95.7$ \\
\hline $\mathrm{SO}_{4}^{2-}, \mathrm{mg} / \mathrm{L}$ & $35.0 \pm 43.3$ & $49.2 \pm 37.7$ & $93.3 \pm 26.2$ & $16.7 \pm 12.0$ & $66.0 \pm 30.0$ \\
\hline TDS, mg/L & $453.0 \pm 233.3$ & $425.5 \pm 213.3$ & $657.3 \pm 151.1$ & $275.5 \pm 195.8$ & $646.2 \pm 223.5$ \\
\hline Hardness, mg/L & $108.6 \pm 65.7$ & $111.6 \pm 69.7$ & $176.5 \pm 88.7$ & $54.7 \pm 46.5$ & $215.3 \pm 85.9$ \\
\hline $\mathrm{HCO}_{3}^{-}, \mathrm{mg} / \mathrm{L}$ & $84.6 \pm 103.7$ & $81.1 \pm 46.8$ & $109.3 \pm 68.8$ & $11.0 \pm 7.6$ & $136.6 \pm 35.5$ \\
\hline $\mathrm{CO}_{3}^{2-}, \mathrm{mg} / \mathrm{L}$ & $0.0 \pm 0.0$ & $0.1 \pm 0.1$ & $0.2 \pm 0.2$ & $0.0 \pm 0.0$ & $0.1 \pm 0.0$ \\
\hline LSI & $-1.9 \pm 2.2$ & $-0.9 \pm 1.5$ & $-0.1 \pm 1.3$ & $-3.6 \pm 1.1$ & $0.1 \pm 0.3$ \\
\hline RSI & $9.3 \pm 3.2$ & $8.1 \pm 2.1$ & $7.0 \pm 1.6$ & $12.0 \pm 1.7$ & $6.5 \pm 0.5$ \\
\hline PSI & $7.8 \pm 3.3$ & $7.1 \pm 1.6$ & $6.3 \pm 1.2$ & $10.8 \pm 1.6$ & $5.5 \pm 0.6$ \\
\hline LSCI & $2.5 \pm 2.1$ & $1.9 \pm 0.7$ & $4.0 \pm 4.0$ & $9.1 \pm 4.5$ & $1.2 \pm 0.8$ \\
\hline
\end{tabular}

Table 7. Summary of chemical analysis and the water quality index for tap water in Lienchiang.

\begin{tabular}{|c|c|c|c|c|c|}
\hline Township & Nangan & Beigan & Xiju Island & Dongju Island & Dongyin \\
\hline Alkalinity, mg/L & $53.0 \pm 1.4$ & $40.0 \pm 0.0$ & $11.0 \pm 1.4$ & $113.0 \pm 1.4$ & $6.0 \pm 0.0$ \\
\hline $\mathrm{pH}$ & $7.6 \pm 0.0$ & $7.9 \pm 0.0$ & $7.6 \pm 0.0$ & $7.4 \pm 0.2$ & $7.0 \pm 0.2$ \\
\hline $\mathrm{Cl}^{-}, \mathrm{mg} / \mathrm{L}$ & $122.5 \pm 6.4$ & $162.5 \pm 3.5$ & $114.0 \pm 0.0$ & $80.9 \pm 3.4$ & $140.7 \pm 8.1$ \\
\hline $\mathrm{SO}_{4}^{2-}, \mathrm{mg} / \mathrm{L}$ & $52.1 \pm 1.9$ & $22.8 \pm 0.6$ & $4.4 \pm 2.2$ & $26.8 \pm 2.1$ & $3.6 \pm 1.5$ \\
\hline TDS, mg/L & $369.0 \pm 14.1$ & $354.5 \pm 7.8$ & $227.5 \pm 12.0$ & $379.5 \pm 6.4$ & $293.3 \pm 12.6$ \\
\hline Hardness, mg/L & $107.0 \pm 5.7$ & $63.4 \pm 0.0$ & $13.9 \pm 8.4$ & $139.0 \pm 0.0$ & $11.5 \pm 4.2$ \\
\hline $\mathrm{HCO}_{3}^{-}, \mathrm{mg} / \mathrm{L}$ & $52.8 \pm 1.4$ & $39.6 \pm 0.0$ & $10.9 \pm 1.4$ & $112.7 \pm 1.3$ & $6.0 \pm 0.0$ \\
\hline $\mathrm{CO}_{3}^{2-}, \mathrm{mg} / \mathrm{L}$ & $0.2 \pm 0.0$ & $0.3 \pm 0.0$ & $0.0 \pm 0.0$ & $0.3 \pm 0.1$ & $0.0 \pm 0.0$ \\
\hline LSI & $0.4 \pm 0.1$ & $0.4 \pm 0.0$ & $-1.2 \pm 0.4$ & $0.6 \pm 0.2$ & $-2.3 \pm 0.4$ \\
\hline RSI & $6.8 \pm 0.1$ & $7.2 \pm 0.0$ & $10.0 \pm 0.7$ & $6.1 \pm 0.2$ & $11.7 \pm 0.5$ \\
\hline PSI & $7.4 \pm 0.1$ & $8.3 \pm 0.0$ & $11.6 \pm 0.8$ & $6.0 \pm 0.0$ & $12.9 \pm 0.3$ \\
\hline LSCI & $3.3 \pm 0.1$ & $4.6 \pm 0.1$ & $10.9 \pm 1.2$ & $1.0 \pm 0.0$ & $24.1 \pm 1.5$ \\
\hline
\end{tabular}

Table 8. Summary of chemical analysis and the water quality index for ground water in Lienchiang.

\begin{tabular}{|c|c|c|c|c|c|}
\hline Township & Nangan & Beigan & Xiju Island & Dongju Island & Dongyin \\
\hline Alkalinity, mg/L & $81.0 \pm 32.5$ & $123.0 \pm 36.1$ & $50.0 \pm 31.1$ & $122.0 \pm 8.5$ & $51.0 \pm 14.8$ \\
\hline $\mathrm{pH}$ & $6.4 \pm 0.4$ & $6.8 \pm 0.5$ & $6.8 \pm 0.4$ & $7.6 \pm 1.2$ & $6.7 \pm 0.3$ \\
\hline $\mathrm{Cl}^{-}, \mathrm{mg} / \mathrm{L}$ & $141.5 \pm 13.4$ & $199.7 \pm 68.5$ & $121.5 \pm 3.5$ & $131.6 \pm 77.0$ & $143.4 \pm 42.1$ \\
\hline $\mathrm{SO}_{4}^{2-}, \mathrm{mg} / \mathrm{L}$ & $42.9 \pm 7.1$ & $58.5 \pm 15.9$ & $23.2 \pm 17.7$ & $39.2 \pm 4.8$ & $51.6 \pm 13.2$ \\
\hline TDS, mg/L & $521.0 \pm 35.4$ & $731.0 \pm 294.7$ & $366.0 \pm 130.1$ & $492.5 \pm 122.3$ & $493.2 \pm 92.1$ \\
\hline Hardness, mg/L & $174.5 \pm 38.9$ & $282.7 \pm 141.4$ & $85.3 \pm 70.3$ & $152.5 \pm 24.7$ & $92.5 \pm 17.4$ \\
\hline $\mathrm{HCO}_{3}^{-}, \mathrm{mg} / \mathrm{L}$ & $81.0 \pm 32.5$ & $127.9 \pm 36.0$ & $50.0 \pm 31.1$ & $120.2 \pm 6.0$ & $50.4 \pm 14.8$ \\
\hline $\mathrm{CO}_{3}^{2-}, \mathrm{mg} / \mathrm{L}$ & $0.0 \pm 0.0$ & $0.1 \pm 0.1$ & $0.0 \pm 0.0$ & $1.7 \pm 2.3$ & $0.0 \pm 0.0$ \\
\hline LSI & $-0.5 \pm 0.6$ & $0.3 \pm 0.6$ & $-0.7 \pm 0.3$ & $0.9 \pm 1.3$ & $-0.9 \pm 0.3$ \\
\hline RSI & $7.3 \pm 0.9$ & $6.3 \pm 0.8$ & $8.1 \pm 1.0$ & $5.8 \pm 1.4$ & $8.4 \pm 0.3$ \\
\hline PSI & $6.4 \pm 0.8$ & $5.4 \pm 1.0$ & $8.0 \pm 1.8$ & $5.9 \pm 0.2$ & $8.0 \pm 0.5$ \\
\hline LSCI & $2.4 \pm 0.7$ & $2.0 \pm 0.4$ & $3.5 \pm 1.9$ & $1.4 \pm 0.5$ & $4.1 \pm 1.3$ \\
\hline
\end{tabular}

\subsection{Penghu}

The chemical analysis results and the calculated water quality indices for the tap water and ground water in Penghu are summarized in Tables 3 and 4, respectively. As compared to the water quality indices of the tap water in the main (Taiwan) island, the values of the LSI, the RSI, and the PSI measured in Penghu (Table 3) do not differ much from those measured on the main island. However, the LSCI values for Penghu (Table 3$)$ are remarkably higher than the values $(0.58 \pm 0.25)$ on the main island, which indicates a high corrosion tendency to stainless steel based on the interpretation of the LSCI. Note that the water source for tap water on the main island comes exclusively from rainfall. In contrast, the amounts of rainfall in all the remote islands of these three counties cannot generally 
afford to be self-sufficient supply for the demand of tap water. As a result, the tap water sources in these remote-island counties are made up from rainfall, ground water, desalinated water, or any combination of these. This leads to the situation of remarkably higher chloride ion concentrations, in comparison with $8.25 \pm 6.40 \mathrm{mg} / \mathrm{L}$ of chloride ion concentrations on the main island, as shown in Table 3. The chloride ion concentrations of the ground water are higher than those for the tap water, except for Chimei (cf. Tables 3 and 4). This could be attributed to the fact that the tap-water source in Chimei relies more on the desalinated water than the ground water.

Both values of the LSCI for the tap water and ground water indicate a high corrosion tendency to stainless steel. Moreover, with such high concentrations of chloride ions in both tap and ground water, the pitting corrosion will easily occur, particularly in the SWHs made from 304 stainless steel according to the study of Huang and Huang [23] (Figure 3). In comparison with 304 stainless steel, 316 stainless steel of the passivation film on the surface has a higher corrosion resistance to chloride ions compared with 304 stainless steel in the measured range of chloride ion concentrations in Penghu.

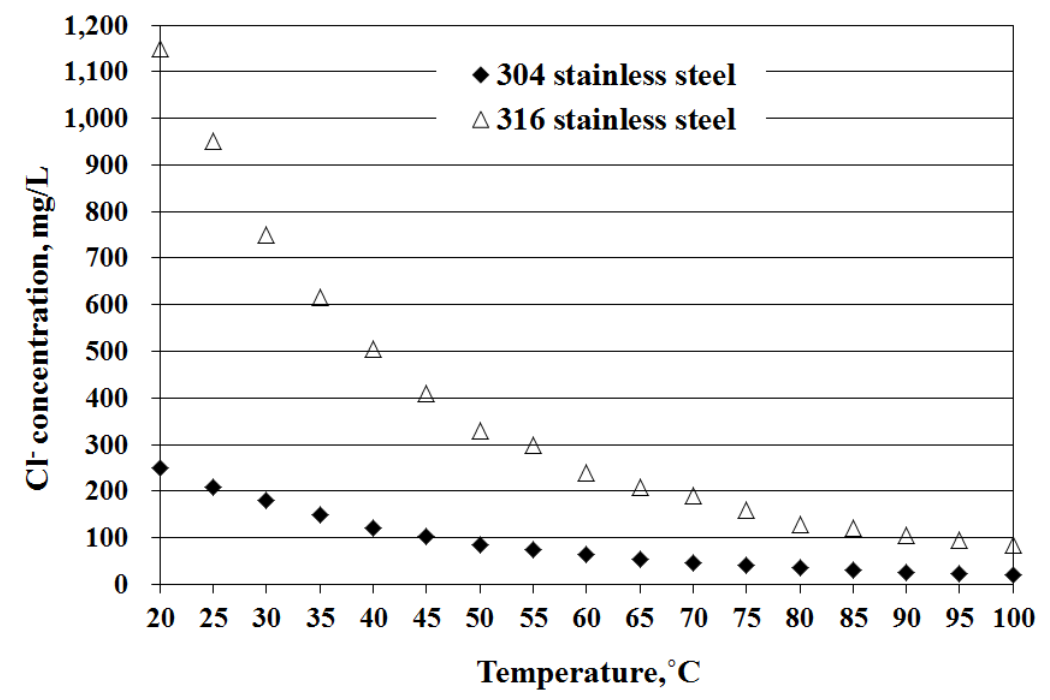

Figure 3. Relationship of concentration limits for stainless steel corroded by chloride ions at $\mathrm{pH}=7$ versus temperature (compiled from the study of Huang and Huang [23]).

Judging from the calculated values of the LSI, the RSI, and the PSI, the use of tap water in the SWHs leads to a slight scaling tendency, while the use of ground water in the SWHs leads to a relatively higher scaling tendency in Penghu, except for Siyu, in which its LSI, RSI, and PSI values for tap water indicate corrosion tendency.

\subsection{Kinmen}

Tables 5 and 6 summarize the chemical analysis results and the calculated water quality indices for the tap water and ground water, respectively, in Kinmen. Except for the tap water of Lieyu, in which the tap-water reservoir is exclusively supplied by rainfall, the chloride ion concentrations of the tap water are remarkable higher than those on the main island, while both chloride ion concentrations of the tap and ground water are relatively lower than those in Penghu. The calculated values of LSCI for the tap water (except for Lieyu) and ground water reveal significant corrosion tendency to stainless steel. Furthermore, in consideration of the working temperatures of SWHs $\left(15-80{ }^{\circ} \mathrm{C}\right)$ and the chloride ion concentrations (Tables 5 and 6) in Kinmen, 316 stainless steel is a better choice than 304 stainless steel in the manufacture of SWHs for the prevention of pitting corrosion at elevated water temperatures in SWHs.

Judging from the calculated values of the LSI, the RSI, and the PSI, there is a slight to serious corrosive tendency for SWHs using either tap water or ground water. 


\subsection{Lienchiang}

Tables 7 and 8 summarize the chemical analysis results and the calculated water quality indices for the tap water and ground water, respectively, in Lienchiang. Similar to the cases of the other two remote-island counties, i.e., Penghu and Kinmen, the chloride ion concentrations of the tap water are remarkably higher than those on the main island, while both chloride ion concentrations of the tap and ground water are lower than those in Penghu. The calculated values of the LSCI for both tap and ground water reveal significant corrosion tendency to stainless steel. With such a high concentration of chloride ions, the same conclusion made for the SWHs installed in Penghu and Kinmen can also be drawn for the case in Lienchiang: 316 stainless steel is a better choice than 304 stainless steel in the manufacture of SWH for the prevention of pitting corrosion at elevated water temperatures in SWHs.

Judging from the calculated values of the LSI, the RSI, and the PSI, there is a slight to serious corrosive tendency, except for Dongju Island, in which the data of these three indices show a slight scaling tendency for SWHs using either tap water or ground water.

\subsection{Comparison among Three Remote-Island Counties}

Comparison of the LSCI and the chloride ion concentration for both ground and tap water among the three investigated counties is summarized in Table 9. Excluding the tap water quality in Lieyu where the tap water is exclusively supplied by rainfall, and the ranges of chloride ion concentration and the LSCI fall within 45-104 mg/L and 1.7-2.8, respectively, in the other townships/cities of Kinmen. As revealed from Table 9a, the ground water in Penghu has the highest concentrations of chloride ions, while the next highest level is Lienchiang. As mentioned previously, the tap-water sources in almost all townships/cities (except for Lieyu) of these three counties rely heavily on ground water, desalinated water, or both. As a result, the level of the chloride ion concentration for tap water in these three counties is close to that for ground water. However, all the LSCI data (except for the tap water of Lieyu) show a significant tendency of pitting corrosion no matter what the value of the chloride ion concentration is. This is because the LSCI is defined by the ratio of the sum of chloride ion concentration plus the sulfate concentration to the alkalinity concentration, i.e., Equation (6). However, the LSCI does not consider the temperature effect in its definition. Based on the study of Huang and Huang [23], the concentration limits of 304 and 316 stainless steel corroded by chloride ions in the water temperature range of $20-100{ }^{\circ} \mathrm{C}$ drop as water temperature increases (Figure 3). Due to the cost concern, most of the SWHs installed in these three remote-island counties were made from 304 stainless steel. In view of the measured chloride ion concentrations and the water temperatures in SWHs $\left(80^{\circ} \mathrm{C}\right.$ in the sunny days of summer), pitting corrosion on 304 stainless steel definitely occurs. In contrast, 316 stainless steel can provide higher corrosion resistance to chloride ions but cannot completely prevent pitting corrosion. It is noted that both 304 and 316 steels are in the family of austenitic stainless steel, which easily suffers from "sensitization" from welding heat. Sensitization is one of the causes of the pitting corrosion near the weld shown in Figure 2b. In fact, a small portion of SWHs installed in Taiwan is made from 444 steel, which is of the family of ferritic stainless steels that possess a higher resistance to pitting corrosion. It has also been reported [24] that some ferritic stainless steels $(444,445,446$, and 447$)$ have been used for the construction located in highly corrosive (caused mainly by chloride ions) coastal and offshore environments. Therefore, this series of ferritic stainless steels could be another good candidate in the manufacture of SWHs to be installed on the three remote-island counties studied herein. 
Table 9. Comparison of the Larson-Skold Corrosive Index (LSCI) and chloride ion concentration for (a) ground water and (b) tap water among three remote-island counties.

\begin{tabular}{cccc}
\hline \multicolumn{4}{c}{ (a) Ground water } \\
\hline County & Penghu & Kinmen & Lienchiang \\
\hline $\mathrm{C} \ell^{-1}, \mathrm{mg} / \mathrm{L}$ & $203-307$ & $69-167$ & $122-200$ \\
$\mathrm{LSCI}$ & $1.2-6.3$ & $1.2-9.1$ & $1.4-4.1$ \\
\hline \multicolumn{4}{c}{$(\mathbf{b})$ Tab water } \\
\hline County & Penghu & Kinmen & Lienchiang \\
\hline $\mathrm{C} \ell^{-1}, \mathrm{mg} / \mathrm{L}$ & $127-282$ & $5.5^{1} / 45^{2}-104$ & $81-162$ \\
$\mathrm{LSCI}$ & $1.2-4.1$ & $0.2^{1} / 1.7^{2}-2.8$ & $1.0-24.1$
\end{tabular}

Notes: ${ }^{1}$ the data for Lieyu. ${ }^{2}$ the data excluding Lieyu. ${ }^{3}$ the chloride ion concentration in main (Taiwan) island: $8.25 \pm 6.40 \mathrm{mg} / \mathrm{L} .{ }^{4} \mathrm{LSCI}$ in main island: $0.58 \pm 0.25$.

\section{Conclusions}

An investigation of water quality in the three remote-island counties was conducted to understand the scaling or corrosion tendencies in SWHs. Three water quality indices including the LSI, the RSI, and the PSI were employed to assess the level of scaling or corrosion tendencies for both tap water and ground water. In addition, the method of the LSCI was also employed in the water quality assessment to understand the corrosion tendency on stainless steel, which is the primary material in the manufacture of SWHs installed in the remote islands of Taiwan. In Penghu, the values of the LSI, the RSI, and the PSI reveal a slight scaling tendency for both tap and ground water, except for the tap water of Siyu, which shows corrosion tendency. In Kinmen and Lienchiang, these three indices reveal a slight to serious corrosion tendency for both tap and ground water, except for Dongju Island, which shows a scaling tendency. As revealed from the high values of the LSCI in this study, the existence of a heavy corrosion tendency on stainless steel is indeed a critical issue to disseminate throughout the remote islands of Taiwan. In consideration of the high chloride ion concentrations and the high water temperatures (up to $80^{\circ} \mathrm{C}$ ) in SWHs, 304 stainless steel, commonly used in the manufacture of SWHs in Taiwan, cannot prevent the occurrence of pitting corrosion. Materials with a high corrosion resistance to chloride ions, such as 316 stainless steel, are preferable in the manufacture of SWHs installed in these three remote-island counties for the extension of the in-use lifetime of SWHs.

Acknowledgments: This work was supported by the Bureau of Energy, Ministry of Economic Affairs, Republic of China under the contract of 104-D0303.

Author Contributions: Keh-Chin Chang was the principal investigator. Kai-Chun Fan and Kung-Ming Chung conducted data analysis. All authors read and approved the final manuscript.

Conflicts of Interest: The authors declare no conflict of interest.

\section{References}

1. Mauthner, F.; Weiss, W.; Spörk-Dür, M. Solar Heat Worldwide: Markets and Contribution to the Energy Supply 2014, 2016 ed.; International Energy Agency: Paris, France, 2016.

2. Chang, K.C.; Lin, W.M.; Chung, K.M. Solar thermal market in Taiwan. Energy Policy 2013, 55, 477-482. [CrossRef]

3. Lin, W.M.; Fan, K.C.; Chang, K.C.; Chung, K.M. Dissemination of solar water heaters in Taiwan: The case of remote islands. Energies 2013, 6, 5101-5113. [CrossRef]

4. Taiwan Water Corporation. The Statistical Yearbook of Taiwan Water Corporation 2013; Taiwan Water Corporation: Taichung, Taiwan, 2014.

5. Langelier, W.F. The analytical control of anti-corrosion water treatment. J. Am. Water Works Assoc. 1936, 28, 1500-1521.

6. Ryznar, J.W. A new index for determining the amount of calcium carbonate scale formed by water. J. Am. Water Works Assoc. 1944, 36, 472-494. 
7. Larson, T.E.; Skold, R.V. Laboratory studies relating mineral quality of water to corrosion of steel and cast iron. Corrosion 1958, 14, 43-46. [CrossRef]

8. Carrier Air Conditioning Company. Handbook of Air Conditioning System Design; McGraw-Hill Books: New York, NY, USA, 1965.

9. Puckorius, P.R. Get a better reading on scaling tendency of cooling water. Power 1983, 127, 79-81.

10. Degrémont, S.A. Water Treatment Handbook, 6th ed.; Lavoisier Publishing: Paris, France, 1991.

11. Seneviratne, M. A Practical Approach to Water Conservation for Commercial and Industrial Facilities; Elsevier: Amsterdam, The Netherlands, 2007; pp. 83-116.

12. Prisyazhniuk, V.A. Prognosticating scale-forming properties of water. Appl. Therm. Eng. 2007, 27, 1637-1641. [CrossRef]

13. Gacem, Y.; Taleb, S.; Ramdani, A.; Senadjki, S.; Ghaffour, N. Physical and chemical assessment of MSF distillate and SWRO product for drinking purpose. Desalination 2012, 290, 107-114. [CrossRef]

14. Cortes, J.E.; Muñoz, L.F.; Gonzalez, C.A.; Niño, J.E.; Polo, A.; Suspes, A.; Siachoque, S.C.; Hernández, A.; Trujillo, H. Hydro-geochemistry of the formation waters in the San Francisco field, UMV basin, Colombia-A multivariate statistical approach. J. Hydrol. 2016, 539, 113-124. [CrossRef]

15. Roy, S.; Edwards, M.A. Effects of $\mathrm{CaCO}_{3}$ Precipitation on Erosion-Corrosion of Non-Leaded Brass Fittings in Portable Water Systems. In Corrosion 2016; NACE International: Vancouver, BC, Canada, 2016.

16. DeZuane, J. Handbook of Drinking Water Quality, 2nd ed.; Van Nostrand Reinholdm: New York, NY, USA, 1997.

17. Gallegos, A.A.; Martinez, S.S.; Ramirez Reyes, J.L. Evaluation of water corrosivity using a corrosion rate model for a cooling water system. J. New Mater. Electrochem. Syst. 2005, 8, 133-142.

18. Liang, C.H.; Zhang, W. Pitting corrosion mechanisms and characteristics of aluminum in solar heating systems. J. Chin. Chem. Soc. 2006, 53, 313-318. [CrossRef]

19. Ghali, E. Corrosion Resistance of Aluminum and Magnesium Alloys Understanding, Performance, and Testing; John Wiley \& Sons: Hoboken, NJ, USA, 2010; pp. 49-77.

20. Parrott, R.; Pitts, H. Chloride Stress Corrosion Cracking in Austenitic Stainless Steel; The Health and Safety Laboratory for the Health and Safety Executive: Buxton, UK, 2011.

21. Kopeliovich, D. Pitting Corrosion. SubsTech Web Site. Available online: http://www.substech.com/ dokuwiki/doku.php?id=pitting_corrosion (accessed on 1 October 2015).

22. Taiwan Water Corporation. 2013 Yearly Water Quality Annual Report; Taiwan Water Corporation: Taichung, Taiwan, 2014.

23. Huang, X.; Huang, C. Effect of chloride ions in cooling water on the material choice of plates in plate heat exchangers. Petrochem. Des. 2006, 23, 44-46.

24. Bell, T. Metal Profile: Ferritic Stainless. Available online: https://www.thebalance.com/metal-profileferritic-stainless-2340133 (accessed on 6 November 2016).

(C) 2016 by the authors; licensee MDPI, Basel, Switzerland. This article is an open access article distributed under the terms and conditions of the Creative Commons Attribution (CC-BY) license (http://creativecommons.org/licenses/by/4.0/). 